Review

\title{
Potential Mechanisms of Action of Curcumin for Cancer Prevention: Focus on Cellular Signaling Pathways and miRNAs
}

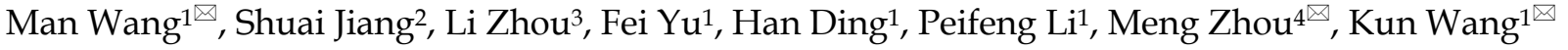 \\ 1. Institute for Translational Medicine, Medical College of Qingdao University, Dengzhou Road 38, Qingdao 266021, China \\ 2. Key Laboratory of Experimental Marine Biology, Institute of Oceanology, Chinese Academy of Sciences, Qingdao 266071, China \\ 3. Animal Biosafety Level III Laboratory at the Center for Animal Experiment, Wuhan University School of Medicine, Wuhan 430071, China \\ 4. Department of Dermatology, Qilu Hospital of Shandong University (Qingdao), Qingdao 266000, China
}

$\square$ Corresponding author: Man Wang, Email: wangman@qdu.edu.cn; Meng Zhou, Email: zhoumeng666@foxmail.com; Kun Wang, Email: wangk696@163.com; Tel: 86-532-82991791

(C) Ivyspring International Publisher. This is an open access article distributed under the terms of the Creative Commons Attribution (CC BY-NC) license (https://creativecommons.org/licenses/by-nc/4.0/). See http://ivyspring.com/terms for full terms and conditions.

Received: 2019.01.31; Accepted: 2019.04.10; Published: 2019.05.07

\begin{abstract}
Despite significant progressions in treatment modalities over the last decade, either cancer incidence or mortality is continuously on the rise throughout the world. Current anticancer agents display limited efficacy, accompanied by severe side effects. In order to improve therapeutic outcomes in patients with cancer, it is crucial to identify novel, highly efficacious pharmacological agents. Curcumin, a hydrophobic polyphenol extracted from turmeric, has gained increasing attention due to its powerful anticancer properties. Curcumin can inhibit the growth, invasion and metastasis of various cancers. The anticancer mechanisms of curcumin have been extensively studied. The anticancer effects of curcumin are mainly mediated through its regulation of multiple cellular signaling pathways, including Wnt/ 3 -catenin, PI3K/Akt, JAK/STAT, MAPK, p53 and NF-KB signaling pathways. Moreover, curcumin also orchestrates the expression and activity of oncogenic and tumor-suppressive miRNAs. In this review, we summarized the regulation of these signaling pathways by curcumin in different cancers. We also discussed the modulatory function of curcumin in the downregulation of oncogenic miRNAs and the upregulation of tumor-suppressive miRNAs. An in-depth understanding of the anticancer mechanisms of curcumin will be helpful for developing this promising compound as a therapeutic agent in clinical management of cancer.
\end{abstract}

Key words: curcumin; cancer; signaling pathways; miRNAs

\section{Introduction}

Cancers are a type of multifaceted disorder where normal cells begin to be hyper-proliferative and initiate the expression of genes that are implicated in cell proliferation, invasion and metastasis [1, 2]. Despite the significant developments in clinical cancer therapy, millions of cancer-associated deaths still occur every year [3]. Available chemotherapeutic agents show limited efficacy, associated with deleterious side effects [4, 5]. Cancer cells could acquire drug resistance which contributes to cancer recurrence in patients [6]. Recently, the concept of chemoprevention by naturally occurring compounds has attracted considerable attention. Therefore, numerous efforts have been put forward to discover novel, highly efficacious anticancer agents from natural sources.

Increasing evidence indicates that naturally derived products show anticancer properties and might be developed as therapeutic agents in cancer management [7-9]. Curcumin (1,7-bis(4-hydroxy-3methoxyphenyl)-1,6-heptadiene-3,5-dione), a natural polyphenolic compound derived from the rhizomes of Curcuma longa (turmeric), is one such agent that is high accessible, cost-effective and safe [10, 11]. 
Turmeric is mainly used as a spice and has an impact on the color, taste and nature of foods [12]. As a traditional curative herb, turmeric has been employed to treat various diseases such as infection, depression and dermatologic diseases [13, 14]. Curcumin is the main active component in turmeric and constitutes approximately $2-5 \%$ of this dietary spice [15]. Curcumin has been demonstrated to possess anti-inflammatory [16], antioxidant [17], anti-microbial [18], cardioprotective [19] and anticancer properties [20]. Notably, the anticancer effects of curcumin have been extensively studied. Curcumin serves as a vital player in cancer progression through interference with multiple cellular signaling cascades including Wnt/ $\beta$-catenin signaling, phosphoinositide 3-kinase (PI3K)/protein kinase B (Akt) pathway, Janus kinase (JAK)/signal transducer and activator of transcription (STAT) signaling pathway, mitogen-activated protein kinase (MAPK) pathway, p53 signaling and nuclear factor-kB (NF-kB) pathway [21]. Recently, curcumin has been found to target oncogenic and tumor-suppressive miRNAs [22]. As a consequence, curcumin is capable of altering multiple cellular targets and signaling pathways that are involved in cancer cell growth, apoptosis, invasion and metastasis. In the review, we highlight diverse aspects of the anticancer effects of curcumin by targeting cancer-related signaling pathways and miRNAs. An in-depth understanding of the anticancer mechanisms of curcumin will increase the possibility of developing this compound as an anticancer drug that might be safe and efficacious in clinical practice.

\section{The anticancer property of curcumin}

Curcumin has been confirmed to exert inhibitory effects on multiple types of cancers [23-25]. Curcumin can regulate cancer cell proliferation, invasion, angiogenesis and metastasis [26]. The molecular basis of the anticancer activities of curcumin is mainly attributed to its profound impacts on multiple cellular signaling molecules (Figure 1). Moreover, curcumin can efficiently downregulate oncogenic miRNAs, and its promotive effects on tumor-suppressive miRNAs have also been well documented. Thus, curcumin holds great promise as a pharmacologically effective agent for cancer treatment.

\section{The $W n t / \beta$-catenin pathway}

The Wnt/ $\beta$-catenin signaling, an evolutionarily conserved pathway, is implicated in the pathogenesis of various human diseases [27]. Dysregulation of this pathway causes the accumulation of $\beta$-catenin in the nucleus and enhances the expression of multiple oncogenes including c-myc and cyclin D1 [28]. Thus, the Wnt/ $\beta$-catenin pathway plays an important role in cancer pathogenesis and may represent a potential target for anticancer therapies. It has been found that the Wnt/ $\beta$-catenin pathway mediates curcumininduced tumor inhibition. Curcumin inhibited proliferation and induced apoptosis of hepatocellular carcinoma (HCC) cells [29]. Mechanistic analysis indicated that curcumin blocked the Wnt/ $\beta$-catenin signaling and reduced glypican-3 (GPC3) expression. Downregulation of GPC 3 could inhibit the expression of $\beta$-catenin, c-myc and cyclin D1, thus enhancing the inhibitory effects of curcumin on the $W n t / \beta$-catenin signaling. GPC3 silencing also promoted curcumin-induced apoptosis and growth inhibition in HCC. These results implied the significant role of the GPC3/Wnt/ $\beta$-catenin signaling pathway in anticancer effects of curcumin on HCC. Another study also verified that curcumin suppressed proliferation and induced apoptosis of HCC cells [30]. Mechanistically, curcumin blocked the Wnt signaling by reducing $\beta$-catenin activity. Curcumin depressed $\beta$-catenin accumulation and also downregulated its target genes c-myc, vascular endothelial growth factor (VEGF) and cyclin D1. Moreover, curcumin was also reported to exert an anti-migratory effect on HCC cells via the Wnt signaling pathway [31]. Curcumin suppressed proliferation and induced apoptosis of breast cancer stem cells (CSCs) [32]. It turned out that inactivation of the $\mathrm{Wnt} / \beta$-catenin pathway contributed to the suppression of breast CSC growth by curcumin. These results provided novel insights into the therapeutic potential of curcumin in breast cancer intervention. Curcumin repressed growth and induced apoptosis of gastric cancer (GC) cells by downregulating target genes (Wnt3a, LRP6, $\beta$-catenin, c-myc and survivin) of the $\mathrm{Wnt} / \beta$-catenin pathway [33]. Curcumin might represent a promising anticancer agent for GC treatment. Curcumin promoted the apoptosis of human endometrial carcinoma cells by decreasing the expression of androgen receptor (AR) and $\beta$-catenin [34]. Upregulation of Wnt3a partially attenuated the inhibitory effects of curcumin on AR expression as well as the proliferation of human endometrial carcinoma cells. Thus, curcumin inhibited the proliferation of human endometrial carcinoma cells via inhibiting $A R$ expression by downregulating the Wnt signaling.

Curcumin inhibited the proliferation of non-small cell lung cancer (NSCLC) cells [35]. Curcumin obviously suppressed the expression of $\beta$-catenin and p-glycogen synthase kinase- $3 \beta$ (GSK-3 $\beta$ ), as well as the expression of downstream cyclin D1 and c-myc. Therefore, curcumin exerted an inhibitory effect on NSCLC proliferation through the 
Wnt/ $\beta$-catenin pathway. Curcumin could restrain colon cancer growth both in vitro and in vivo [36]. The anticancer effect of curcumin was mediated by inhibition of the Wnt/ $\beta$-catenin pathway. Curcumin was shown to inhibit the proliferation of medulloblastoma cells [37]. Curcumin treatment activated GSK-3 $\beta$, and thus downregulated $\beta$-catenin and its downstream target cyclin D1. The inhibition of $\beta$-catenin led to the inactivation of the $\mathrm{Wnt} / \beta$-catenin pathway. In conclusion, curcumin was able to restrain medulloblastoma growth by targeting the Wnt/ $\beta$-catenin signaling pathway.

Epithelial-mesenchymal transition (EMT) is tightly associated with the initial stage of tumor invasion and metastasis, whereby cancer cells lose the characteristics of epithelial cells, gain mesenchymal phenotypes and invade the surrounding tissues [38]. The EMT process in cancer is controlled by multiple signaling cascades including the $\mathrm{Wnt} / \beta$-catenin pathway [39]. Curcumin was able to block the EMT process by inhibiting the Wnt signaling pathway and increasing naked cuticle homolog 2 (NKD2) expression in colon cancer cells [40]. Depletion of NKD2 counteracted curcumin-induced suppression of the Wnt pathway, contributing to downregulation of E-cadherin and upregulation of vimentin. Thus, curcumin could depress the invasion and metastasis of colon cancer cells through NKD2-mediated downregulation of the Wnt signaling pathway. Metastasis-associated protein 1 (MTA1) upregulation is strongly associated with tumor aggressiveness and metastasis [41]. Curcumin was found to limit the proliferation and invasion of NSCLC cells through MTA1-mediated inactivation of the Wnt/ $\beta$-catenin pathway [42]. This study provided a novel perspective on the anticancer mechanism of curcumin in NSCLC.

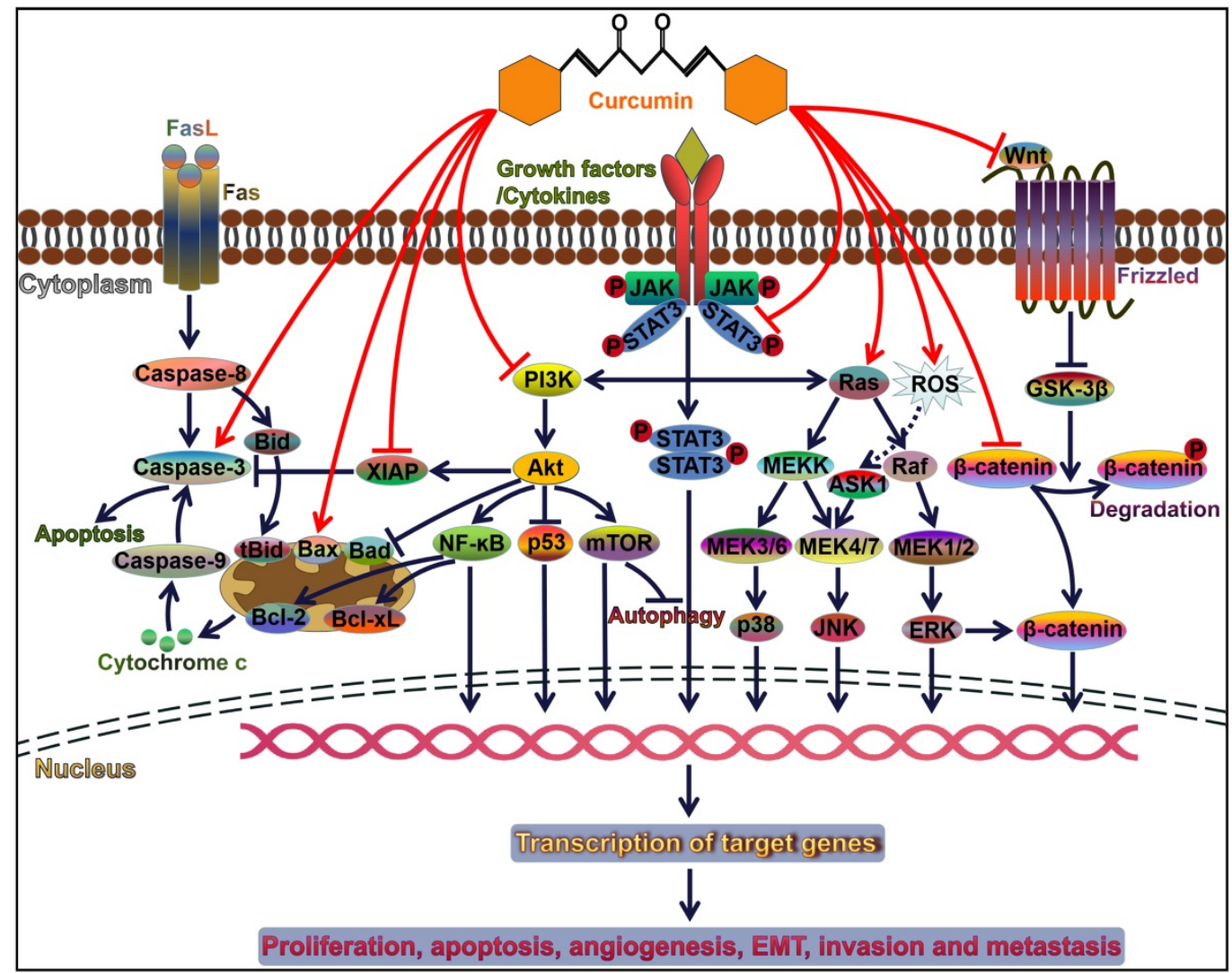

Figure 1. Curcumin modulates cancer progression by controlling diverse signal transduction pathways. Attachment of ligands (e.g., growth factors and cytokines) to their corresponding receptors induces the activation of downstream signaling pathways, such as PI3K/Akt, JAK/STAT, and MAPK pathways. These pathways play an important role in cell survival, proliferation, apoptosis, angiogenesis, invasion and metastasis. Curcumin can orchestrate these three pathways and thus serves a pivotal role in cancer progression. Akt activation restrains the p53 signaling and Bad-mediated apoptotic pathway contributing to cancer cell survival. Akt also initiates the NF-KB signaling pathway. NF-KB favors the expression of anti-apoptotic proteins Bcl-2 and Bcl-xL, thereby leading to the inhibition of cancer cell apoptosis. Curcumin acts as an inhibitor of NF-KB and functions in activating the caspase cascade. Therefore, curcumin facilitates cancer cell apoptosis. Wnt binds to Frizzled receptor to trigger the canonical Wnt pathway. In the absence of Wnt signaling, GSK3- $\beta$ induces the phosphorylation of $\beta$-catenin and results in its degradation. Wnt binding to its receptor can inhibit the activation of GSK3- $\beta$, thus allowing stabilization and accumulation of $\beta$-catenin in the cytoplasm. Accumulated $\beta$-catenin eventually translocates into the nucleus and induces the expression of multiple oncogenes and EMT-inducing transcription factors. Curcumin is capable of repressing the EMT process in cancer cells through inactivation of the Wnt/B-catenin signaling. FasL, Fas ligand; Bid, BH3-interacting domain death agonist; tBid, truncated Bid; Bcl-2, B-cell lymphoma-2; Bax, Bcl-2-associated X protein; Bad, Bcl-2-associated death promoter; Bcl-xL, B-cell lymphoma-extra-large; XIAP, X-linked inhibitor of apoptosis protein; PI3K, phosphoinositide 3-kinase; Akt, protein kinase B; NF-KB, nuclear factor-KB; mTOR, mammalian target of rapamycin; JAK, Janus kinase; STAT, signal transducer and activator of transcription; MEK, mitogen-activated protein kinase kinase; MEKK, MEK kinase; ROS, reactive oxygen species; ASK1, apoptosis signal-regulating kinase 1; JNK, c-Jun N-terminal kinase; ERK, extracellular signal-regulated kinase; GSK-3 $\beta$, glycogen synthase kinase-3 $\beta$. 


\section{The PI3K/Akt pathway}

The PI3K/Akt pathway controls a variety of cellular processes, such as cell proliferation and metabolism [43]. The misregulation of PI3K/Akt signaling pathway is commonly correlated with carcinogenesis and cancer progression [44]. Curcumin markedly suppressed the proliferation of breast cancer cells [45]. Curcumin induced cell cycle arrest by downregulating cell division cycle 25 (CDC25) and CDC2 while upregulating p21. It also inactivated the $\mathrm{Akt} / \mathrm{mammalian}$ target of rapamycin (mTOR) signaling and the downstream targets, which were upstream of cell cycle proteins, indicating that curcumin might induce cell cycle arrest through suppression of the Akt/mTOR pathway. In addition, curcumin reduced B-cell lymphoma-2 (Bcl-2) and upregulated Bcl-2-associated $X$ protein (Bax) and cleaved caspase-3, thus promoting breast cancer cell apoptosis. Inhibition of the Akt/mTOR pathway might be one of the mechanisms underlying the anti-proliferative activity of curcumin in breast cancer. Inhibition of PI3K augmented curcumin-induced cell death, apoptosis, and autophagy via regulating the expression of $\mathrm{Bcl}-2$ family members in breast cancer cells [46]. Thus, inactivation of the PI3K/Akt pathway might boost the antineoplastic effect of curcumin on breast cancer. Curcumin suppressed the growth of liver cancer stem cells (LCSCs) and promoted cell apoptosis [47]. Curcumin could target the PI3K/Akt/mTOR signaling pathway. Reversely, activation of PI3K/Akt counteracted curcumin-mediated growth inhibition of LCSCs. Curcumin inhibited LCSC progression via the PI3K/Akt/mTOR signaling pathway. Therefore, curcumin might be an effective agent against liver cancer.

Curcumin reduced the viability of NSCLC cells, and induced cell apoptosis and autophagy [48]. It significantly attenuated the PI3K/Akt/mTOR pathway. Suppression of mTOR or PI3K/Akt promoted curcumin-induced NSCLC cell death. Curcumin might play an inhibitory role in NSCLC growth by repression of the $\mathrm{PI} 3 \mathrm{~K} / \mathrm{Akt} / \mathrm{mTOR}$ pathway. Likewise, another study showed that curcumin repressed NSCLC cell proliferation, induced cell apoptosis and upregulated caspase-3 by targeting the PI3K/Akt signaling pathway [49]. Curcumin was able to promote the apoptosis of renal cell carcinoma (RCC) cells by downregulating Bcl-2 and upregulating Bax [50]. It also induced cell cycle arrest by reducing the expression of cyclin B1. Moreover, curcumin inhibited the activation of the PI3K/Akt signaling pathway. These results indicated that the PI3K/Akt signaling pathway mediated the anticancer effect of curcumin on RCC. Curcumin promoted the apoptosis of ovarian cancer cells via upregulating caspase-3 and Bax by blocking the PI3K/Akt pathway [51]. Moreover, it also suppressed ovarian cancer cell invasion and impeded cell cycle progression. Curcumin possessed the therapeutic potential for ovarian cancer. Curcumin remarkably inhibited pancreatic cancer (PC) cell proliferation through upregulation of $\mathrm{p} 21^{/ \mathrm{CIP} 1}$ and $\mathrm{p} 27 / \mathrm{KIP} 1$ as well as downregulation of cyclin D1 [52]. It also promoted the apoptosis of PC cells by reducing the Bcl-2/Bax ratio and activating caspase-9/3. Further study demonstrated that curcumin increased the expression of forkhead box O1 (FOXO1) through suppression of the PI3K/Akt signaling, contributing to cell cycle arrest and apoptosis. These results provided evidence for a mechanism underlying the anti-carcinogenic property of curcumin. Previously, curcumin was found to restrain the PI3K/Akt pathway and its downstream target NF-kB in lymphoma cells [53]. This resulted in the enhancement of radiation-induced apoptosis in lymphoma cells. Therefore, curcumin might be exploited as a radiation sensitizer in the treatment of lymphoma.

Curcumin inhibited superoxide dismutase (SOD)-mediated invasion and migration of PC cell [54]. SOD-induced upregulation of p-Akt and p-NF-kB could be weakened by curcumin. Summarizing, curcumin could block PC metastasis by inactivating the PI3K/Akt/NF-kB pathway. Curcumin restrained the growth, invasion and migration of thyroid cancer cells [55]. Mechanistically, curcumin suppressed the phosphorylation of PI3K and Akt signaling pathways and consequently reduced the expression of matrix metalloproteinase $(\mathrm{MMP}) 1 / 7$ and cyclooxygenase-2 (COX-2). Collectively, curcumin inhibited thyroid cancer cell invasion and migration by targeting the PI3K/Akt signaling pathway. Curcumin obviously restrained the proliferation, invasion and migration of human colon cancer cells [56]. Curcumin inhibited the activation of the PI3K/Akt pathway in colon cancer cells, thus affecting the expression of the downstream proteins caspase-3, cytochrome-c (Cyto-c), Bcl-2 and Bax. Moreover, combination of the PI3K/Akt inhibitor and curcumin resulted in a significantly synergistic effect against invasion and migration of colon cancer cells. Collectively, curcumin might be a potential anticancer agent against human colon cancer.

\section{The JAK/STAT signaling pathway}

Cytokines can bind to specific receptors and allow transactivation of JAKs [57]. STAT transcription factors are then recruited to the intracellular domains 
of the receptors. STATs are imported into the nucleus and initiate the expression of cytokine-responsive genes. The JAK/STAT pathway performs a critical role in cytokine-mediated immune responses [58]. Dysregulation of the JAK/STAT pathway is considered as a vital contributor to the aetiology of various cancers [59]. The JAK/STAT pathway may represent a potential target for cancer management and drug development. Curcumin remarkably suppressed the viability, invasion and migration, but induced apoptosis of retinoblastoma cells [60]. In terms of mechanism, curcumin reduced the phosphorylation of JAK1, STAT1 and STAT3. The anticancer activity of curcumin appeared to be mediated via deactivation of the JAK/STAT pathway. Curcumin could evidently inhibit NSCLC growth and repressed tumor angiogenesis in vivo [61]. Mechanistic analysis revealed that curcumin suppressed the phosphorylation of JAK and STAT3, which led to the downregulation of VEGF, B-cell lymphoma-extra large (Bcl-xL) and cyclin D1. As a consequence, upregulation of STAT3 abrogated the anti-angiogenic activity of curcumin in NSCLC. Based on these results, curcumin might be a potential STAT3-targeting agent for NSCLC therapy. Curcumin also functioned as a potential inhibitor of angiogenesis in laryngeal squamous cell carcinoma (LSCC) cells [62]. Mechanistic study demonstrated that curcumin inhibited JAK-2 expression and pSTAT-3 production, hence downregulating MMP-2 and VEGF. These studies implied that the anticancer property of curcumin might involve its inhibitory effects on vasculogenic mimicry. Further clinical studies are demanded to evaluate the efficacy of curcumin as an anti-angiogenic agent in cancer therapy. The anti-carcinogenic mechanism of curcumin in small cell lung cancer (SCLC) was also explored [63]. Curcumin was capable of downregulating STAT3 in SCLC cells. Accordingly, curcumin inhibited the expression of STAT3 downstream targets including cyclin B1, Bcl-xL, survivin, VEGF, MMP-2/7 and intercellular adhesion molecular-1 (ICAM-1), which led to the inhibition of SCLC cell proliferation, invasion and migration. Depletion of STAT3 also elicited anti-invasive effects on SCLC cells. On the contrary, activation of interleukin-6 (IL-6), an upstream activator of STAT3, promoted cancer cell proliferation, survival, angiogenesis, invasion and migration. These results uncovered the significance of the IL-6/JAK/STAT3 signaling in SCLC progression.

\section{The MAPK signaling pathway}

The MAPKs are a large family of serine/threonine kinases and consist of three subfamilies, p38 MAPKs, c-Jun N-terminal kinases (JNKs) and extracellular signal-regulated kinases (ERKs) [64, 65]. MAPK signaling cascades govern a variety of biological processes including cell proliferation, immune responses and carcinogenesis [66]. Curcumin suppressed the proliferation and migration of human placental choriocarcinoma cells [67]. It also induced choriocarcinoma cell apoptosis. Curcumin activated the ERK1/2 and stress-activated protein kinase (SAPK)/JNK MAPK signaling pathways. Accordingly, the downstream molecules (e.g., c-Jun and P90RSK) of these signaling pathways were upregulated by curcumin. Moreover, the phosphorylation of MAPK kinases partially mediated the anticancer effects of curcumin. These findings demonstrated that curcumin functioned as a novel chemotherapeutic drug against choriocarcinoma cells. Curcumin could decrease the viability of retinoblastoma cells [68]. Curcumin impeded cell cycle progression by downregulating cyclin D3 and cyclin-dependent kinase $(\mathrm{CDK}) 2 / 6$ as well as elevating the expression of CDK inhibitors p21 and p27. Curcumin was able to activate caspase-3/9 and thus promoted retinoblastoma cell apoptosis. Moreover, curcumin also triggered the phosphorylation of JNK and p38 MAPK. Inhibition of JNK/p38 MAPK offset curcumin-induced cancer cell apoptosis. Collectively, curcumin induced retinoblastoma cell apoptosis by activating JNK and p38 MAPK pathways. Curcumin could inhibit the growth of lung adenocarcinoma cells [69]. Moreover, curcumin induced lung adenocarcinoma cell apoptosis by activating caspase- $3 / 9$, increasing the $\mathrm{Bax} / \mathrm{Bcl}-2$ ratio and inducing Cyto-c translocation. More importantly, curcumin induced the activation of c-JNK, p38 and ERK, suggesting that MAPK signaling pathways were involved in curcumin-induced apoptosis of lung adenocarcinoma cells. Curcumin restrained the proliferation of human monocytic leukemia cells by inducing cell cycle arrest [70]. It also activated p38 MAPK and JNK, leading to elevated Fas ligand (FasL) expression, decreased Bcl-2 expression and NF-kB downregulation. Accordingly, these events contributed to caspase-3 activation and leukemia cell apoptosis. Therefore, curcumin induced human monocytic leukemia cell apoptosis by activating MAPK-related signaling pathways. In addition, curcumin inhibited the invasion of human monocytic leukemia cells by descending the expression of MMP-2/9. These findings provide a theoretical basis for further investigations on the therapeutic potential of curcumin in human acute leukemia. 


\section{The p53 signaling pathway}

The tumor suppressor p53 plays an important role in the pathogenesis of human cancers [71]. Activation of the p53 signaling could prevent cancer cell proliferation and induce cell apoptosis [72, 73]. Curcumin repressed proliferation and promoted autophagy and apoptosis in GC cells [74]. Mechanistic investigation demonstrated that curcumin could increase the expression of p53 and p21, thus activating the p53 signaling pathway. Additionally, curcumin also inactivated the PI3K signaling pathway. These results revealed the mechanism of curcumin in the suppression of GC progression, thus providing an effective therapeutic measure for GC. Curcumin suppressed the invasiveness of oral squamous cell carcinoma (OSCC) by reducing the expression of MMP-2/9 [75]. It also inhibited the EMT process in OSCC cells through upregulation of p53 expression. Curcumin might be exploited as an adjunctive regimen for OSCC treatment. Curcumin was demonstrated to inhibit the proliferation of multiple myeloma (MM) cells [76]. Further study revealed that curcumin could enhance MM cell apoptosis by upregulating p53. These findings might provide evidence for the clinical application of curcumin in cancer intervention. Curcumin also enhanced the anticancer action of paclitaxel in human papilloma virus (HPV)-positive cervical cancer cells via the NF-KB/p53/caspase-3 pathway [77]. Curcumin in conjunction with paclitaxel might represent a superior therapeutic strategy for the treatment of human cervical cancer.

\section{The NF-kB signaling pathway}

Curcumin is a dietary inhibitor of NF-kB. Previous study confirmed that curcumin could effectively repress acidic bile-induced NF-KB activation and pre-neoplastic events in human hypopharyngeal cells [78]. More importantly, curcumin downregulated NF- $\mathrm{kB}$ transcription factors, c-REL, p65, anti-apoptotic Bcl-2, oncogenic TNF-a and STAT3. Curcumin inhibited acidic bile-induced oncogenic mRNA phenotype in hypopharyngeal cells. Curcumin might be useful for the prevention of hypopharyngeal neoplasia. Curcumin improved the pro-apoptotic effect of irradiation on oesophageal squamous cell carcinoma (ESCC) both in vitro and in vivo [79]. Further study indicated that curcumin significantly suppressed the phosphorylation of inhibitor of kappa $\mathrm{Ba}(\mathrm{I} \kappa \mathrm{Ba})$, which in turn resulted in the degradation of NF- $\mathrm{kB}$. Curcumin tremendously reduced the expression of the downstream effector proteins (cyclin D1 and Bcl-2). Thus, curcumin synergistically boosted the pro-apoptotic effect of irradiation through blockade of the NF-kB pathway.
Curcumin suppressed autocrine growth hormone $(\mathrm{GH})$-mediated invasion and metastasis of breast cancer cells [80]. Curcumin also triggered caspase-mediated apoptotic cell death. Mechanistically, curcumin depressed the phosphorylation of p65 and thus partially lowered its DNA binding capability in breast cancer cells. The targeting of the NF- $\mathrm{kB}$ signaling by curcumin might be a treatment option for breast cancer.

\section{The apoptotic pathways}

Curcumin alone or in conjunction with chemotherapeutic agents is capable of promoting apoptosis in diverse types of cancers [81]. Emerging evidence verifies that curcumin is able to orchestrate apoptotic signaling pathways in cancer cells [82, 83]. Curcumin showed cytotoxic activity against human glioma cells [84]. Curcumin induced the activation of caspases and cleavage of poly (ADP-ribose) polymerase (PARP), and elevated the $\mathrm{Bax} / \mathrm{Bcl}-2$ ratio. Curcumin also reduced the mitochondrial membrane potential and promoted the production of reactive oxygen species (ROS). Thus, curcumin could initiate apoptosis in glioma cells. Curcumin could suppress the proliferation of GC cells [85]. Curcumin also promoted GC cell apoptosis by activating caspase-3/9 and decreasing the $\mathrm{Bcl}-2 / \mathrm{Bax}$ ratio. Meanwhile, curcumin robustly promoted GC cell autophagy by inducing conversion of microtubule-associated protein-1 light chain 3 (LC3)-I to LC3-II and upregulating autophagy-related proteins. Inhibition of autophagy by 3-methyladenine (3-MA) led to enhanced curcumin-induced cell apoptosis. It seemed that curcumin triggered protective autophagy in GC cells. The combination of curcumin and autophagy inhibitor might represent a potential therapeutic strategy for GC treatment. Another report revealed that curcumin induced ROS generation and GC cell apoptosis [86]. Remarkably, curcumin activated apoptosis signal-regulating kinase 1 (ASK1), upregulated the upstream JNK activator, mitogen-activated protein kinase kinase 4 (MKK4), and induced the phosphorylation of JNK in GC cells. Inhibition of ROS production prevented curcumin-induced ASK1/MKK4/JNK signaling and cell apoptosis. Therefore, curcumin induced GC cell apoptosis by the ROS-activated ASK1-MKK4-JNK pathway.

The pro-apoptotic activity of curcumin in HCC has also been investigated. It was found that curcumin induced the release of Cyto-c, loss of mitochondrial membrane potential and the activation of caspase-3/9 and PARP in HCC cells [87]. p73, a member of the p53 family, is responsive to the DNA damage that contributes to cell apoptosis $[88,89]$. The 
p73 gene can encode a tumor suppressor, transactivation-competent p73 (TAp73), and an oncogenic isoform, dominant-negative p73 (DNp73) $[90,91]$. Curcumin induced DNA damage and raised the TAp73/DNp73 ratio in HCC cells [87]. These results indicated that curcumin could induce HCC cell apoptosis through a TAp73/DNp73 dependent mechanism. Curcumin was reported to enhance the antitumor effect of the Bcl-2 inhibitor ABT-737 on HCC cells [92]. Notably, curcumin could increase caspase-3 capability and elevate ROS levels in HCC cells, indicating that curcumin promoted the pro-apoptotic activity of ABT-737. Moreover, the constant activation of the ROS/ASK1/JNK pathway might be a vital mediator of the synergistic effect of curcumin and ABT-737. The combination of curcumin and ABT-737 might provide a potential therapeutic strategy for HCC. Another study also showed that curcumin inhibited proliferation and induced apoptosis of HCC cells through downregulating Notch1 expression [93]. However, further studies are required to elucidate the mechanisms underlying the induction of HCC cell apoptosis by curcumin-mediated Notch1 downregulation.

Curcumin could inhibit the proliferation of NSCLC cells [94]. It could enhance NSCLC cell apoptosis by elevating the $\mathrm{Bax} / \mathrm{Bcl}-2$ ratio. Curcumin descended the mitochondrial membrane potential and induced the release of Cyto-c. Thus, the mitochondrial apoptotic pathway might be implicated in curcumin-induced NSCLC cell apoptosis. Curcumin was reported to enhance cisplatin-induced apoptosis in NSCLC cells [95]. Mechanistically, curcumin downregulated cyclin D1 and upregulated p21. It also induced the activation of apoptotic protease activating factor-1 (Apaf-1) and caspase-9. Therefore, curcumin inhibited the growth of NSCLC via the intrinsic apoptotic pathway. Curcumin suppressed growth and enhanced apoptosis of head and neck squamous cell carcinoma (HNSCC) [96]. Mechanistic exploration indicated that curcumin induced the activation of caspase-8/9, suggesting that curcumin was able to activate both the intrinsic and extrinsic apoptotic pathways in HNSCC cells. The anti-tumorigenic activity of curcumin in HNSCC was associated with the activation of sirtuin 1 (SIRT1) and the suppression of NF-kB. Curcumin significantly inhibited growth and induced apoptosis of cholangiocarcinoma (CCA) [97]. Further study showed that curcumin upregulated the expression of PARP, increased caspase activity and reduced the expression of cyclin D1. In addition, curcumin lowered the expression of Notch1, hairy and enhancer of split-1 (HES-1) and survivin in CCA cells. These findings provided new evidence for a potential anti-carcinogenic mechanism of curcumin. Curcumin could induce the cleavage of PARP and caspase-3/8/9 in NCCIT human embryonic carcinoma cells [98]. Functional analysis indicated that curcumin promoted the apoptosis of NCCIT cells through downregulation of octamer-binding transcription factor 4 (Oct4) and activation of GSK-3 $\beta$. Curcumin might be an effective cancer chemopreventive agent.

Curcumin also promoted apoptosis and suppressed proliferation of melanoma cells [99]. Curcumin upregulated pro-apoptotic Bax and lowered the expression of anti-apoptotic myeloid cell leukemia-1 (Mcl-1) and Bcl-2. It also induced the cleavage of caspase-3/8 and regulated the expression of apoptosis-related proteins (p38, p53 and NF-kB). Curcumin might be exploited as an effective chemopreventive agent against melanoma. Curcumin promoted ROS generation and reduced the mitochondrial membrane potential events, resulting in the apoptosis of neuroblastoma cells [100]. It could increment the expression of Bcl-2-associated death promoter (Bad). Curcumin-induced apoptosis was associated with phosphatase and tensin homolog (PTEN)/Akt/forkhead box O3a (Foxo3a) activity in neuroblastoma cells. These results offered a theoretical basis of the translational application of curcumin. Curcumin exhibited cytotoxicity and anti-proliferative activity on leukemic cells [101]. Curcumin promoted leukemic cell apoptosis by causing the loss of mitochondrial membrane potential, enhancing ROS generation as well as activating caspase-3/9 and PARP. High concentrations $(80 \mu \mathrm{M})$ of curcumin remarkably increased the level of ROS, induced the release of Cyto-c and activated caspase-3, thus promoting osteosarcoma cell apoptosis [102]. Inhibition of ROS generation resulted in the blockade of curcumin-induced apoptosis. Summarizing, curcumin induced the apoptosis of osteosarcoma cells by activating the mitochondrial apoptotic pathway.

\section{The autophagic pathways}

Curcumin has been found to induce autophagy in a variety of cancer cells. Curcumin suppressed the proliferation and enhanced autophagy in colon cancer cells [103]. Curcumin induced p62 degradation and raised LC3 expression, demonstrating that curcumin could promote autophagy in colon cancer cells. Curcumin also inhibited Yes-associated protein (YAP) expression in colon cancer cells. Upregulation of YAP expression could reverse the effect of curcumin on colon cancer cell autophagy. Ganglioside GD3 plays a central role in autophagosome biogenesis and maturation [104]. Curcumin initiated autophagy in 
human lung carcinoma cells by promoting the intracellular localization of LC3 [105]. Human GD3 synthase (hST8Sia I) that catalyzed ganglioside GD3 synthesis was obviously upregulated in lung carcinoma cells. It was speculated that curcumin induced autophagy in lung carcinoma cells by upregulating hST8Sia I. Curcumin was reported to exhibit cytotoxicity against human acute lymphoblastic leukemia (ALL) cells [106]. Further study indicated that curcumin was able to induce autophagy in ALL cells by activating the Raf/MAPK kinase (MEK)/ERK pathway. Collectively, induction of autophagy was an alternative anticancer mechanism of curcumin.

Intriguingly, curcumin displayed dual effects on RCC cells [107]. Low concentrations (5 or $20 \mu \mathrm{M}$ ) of curcumin could protect RCC cells from death by targeting the AMP-activated protein kinase (AMPK) and endoplasmic reticulum (ER) stress pathways. In contrast, high concentrations $(80 \mu \mathrm{M})$ of curcumin induced cell autophagy through regulation of the oxidative stress pathway. Thus, autophagy might be a mechanism for the cytotoxic effects of curcumin on RCC cells. Curcumin induced the apoptosis of osteosarcoma cells by upregulating Bax and cleaved caspase-3 [108]. Suppression of apoptosis enhanced curcumin-induced cell autophagy through upregulation of the JNK signaling pathway. Similarly, inhibition of autophagy promoted curcumin-induced cell apoptosis. Thus, curcumin-induced autophagy might have an anti-apoptotic function in osteosarcoma cells. These findings shed light on the interaction between autophagy and apoptosis in osteosarcoma cells and provided theoretical evidence for the clinical application of curcumin. Transcription factor EB (TFEB) is a master modulator of autophagy and lysosome function [109]. Curcumin was found to activate the TFEB/lysosome pathway, thereby triggering autophagy in human colon cancer cells [110]. Blockade of autophagy resulted in enhanced cell death in colon cancer cells. Autophagy might serve as a survival mechanism to protect cancer cells from curcumin-induced cell death. This study provided a new insight into the modulatory effect of curcumin on autophagy.

Curcumin repressed the proliferation and migration of breast cancer cells [111]. Curcumin elevated LC3-II expression, thus activating autophagy in breast cancer cells. Suppression of autophagy attenuated anti-proliferative and anti-migratory activities of curcumin on breast cancer cells. Curcumin reduced the expression of Akt. Accordingly, upregulation of Akt reversed the effects of curcumin on breast cancer progression. Moreover, AMPK was involved in curcumin-induced autophagy. AMPK activation by curcumin initiated autophagy resulting in Akt degradation and consequent repression of cancer cell survival and migration. Curcumin was verified to exhibit anti-proliferative and anti-invasive characteristics against human melanoma cells [112]. Mechanistically, curcumin promoted autophagic cell death by inactivating the PI3K/Akt/mTOR signaling pathway. Collectively, curcumin might have an effective anti-melanoma potency.

\section{Regulation of oncogenic miRNAs by curcumin}

Curcumin can regulate multiple targets, such as apoptotic proteins, cell cycle regulators, growth factors, receptors, protein kinases, transcription factors, oncoproteins and tumor suppressors (Figure 2). Intriguingly, curcumin also affect the expression of miRNAs, thus modulating numerous molecular targets and signal transduction cascades. Curcumin was found to modulate the expression of oncogenic (miR-19a and miR-19b) and tumor-suppressive miRNAs (miR-15a, miR-16, miR-34a, miR-146b-5p and miR-181b) in breast cancer cells [113]. The regulatory role of curcumin in miRNA expression resulted in the inhibition of carcinogenesis and metastasis, and promotion of apoptosis in breast cancer cells. Curcumin might function as a vital miRNA regulator in breast cancer. GH signaling serves as a promoting factor in breast cancer progression by upregulating miR-182-96-183 cluster [114]. Curcumin blocked GH-induced metastasis in breast cancer cells by impeding the NF-kB signaling and reducing miR-182-96-183 cluster expression [115]. As a consequence, curcumin promoted the apoptosis of breast cancer cells. Curcumin was found to directly downregulate the oncogenic miR-7641, which in turn led to the suppression of malignant potential in bladder cancer [116]. As expect, curcumin regulated the target of miR-7641, p16. Oppositely, miR-7641 upregulation promoted the tumorigenicity of immortalized bladder cells. These results confirmed that miR-7641 was involved in the anti-carcinogenic activity of curcumin in bladder cancer. Curcumin might possess the potential to be exploited as an effective agent against bladder cancer. Curcumin could abate the proliferation of colorectal carcinoma (CRC) cells by targeting the Wnt/ $\beta$-catenin pathway [36]. In addition, curcumin reduced the expression of miR-130a. Notably, miR-130a upregulation could counteract the anticancer activity of curcumin. miR-130a might be a novel target of curcumin for CRC treatment. miR-214 upregulation enhanced the cisplatin-resistance of ovarian cancer cells [117]. Curcumin was capable of reducing cisplatin-resistance in ovarian cancer cells partly by 
reducing extracellular vesicle-mediated transfer of miR-214. Curcumin showed anticancer activities in chronic myelogenous leukemia (CML) cells by upregulating PTEN, a target of miR-21 [118]. Moreover, curcumin caused the downregulation of miR-21 in CML cells through selective packaging of miR-21 in exosomes. It was likely that encapsulation of oncogenic miR-21 into exosomes might contribute to the anti-leukemic activity of curcumin. Upregulation of miR-125a-5p could facilitate the growth and invasiveness of nasopharyngeal carcinoma (NPC) cells [119]. Curcumin attenuated the expression of miR-125a-5p while enhanced that of tumor protein p53 (TP53) in NPC cells. Consequently, curcumin restricted the proliferation, invasion and migration of NPC cells. These findings might lay a foundation for miRNA-based anticancer therapeutics in NPC.

\section{Modulation of tumor-suppressive miRNAs by curcumin}

Curcumin showed cytotoxicity against schwannoma cells [120]. Curcumin induced the apoptosis of cancer cells by activating PARP and caspase-3/9. Curcumin also increased the expression of miR-344a-3p. Overexpression of miR-344a-3p led to increased $\mathrm{Bax} / \mathrm{Bcl}-2$ ratio. On the contrary, downregulation of miR-344a-3p suppressed the activation of caspase-3/9. Thus, curcumin promoted apoptosis in schwannoma cells by upregulating miR-344a-3p. The expression of miR-491 in colon cancer tissues was reduced, while paternally expression gene-10 (PEG10), Wnt1, and $\beta$-catenin was upregulated compared with adjacent normal tissues [121]. miR-491 overexpression resulted in the downregulation of PEG10, Wnt1 and $\beta$-catenin in CRC cells. Curcumin elevated the expression of miR-491, thus suppressing PEG10 and the Wnt/ $\beta$-catenin signaling pathway. Further study indicated that curcumin inhibited proliferation and induced apoptosis of CRC cells via the miR-491/PEG10 pathway. These findings laid a foundation for further investigations on the anticancer mechanism of curcumin in colon cancer. The combination of curcumin with dihydroartemisinin (DHA) synergistically raised the expression of miR-124 in human ovarian cancer cells [122]. miR-124 could directly interact with midkine (MK), contributing to MK downregulation. Consequently, the combination of curcumin with DHA tremendously suppressed the growth of ovarian cancer cells. Curcumin in combination with DHA might represent a promising therapeutic approach against ovarian cancer.

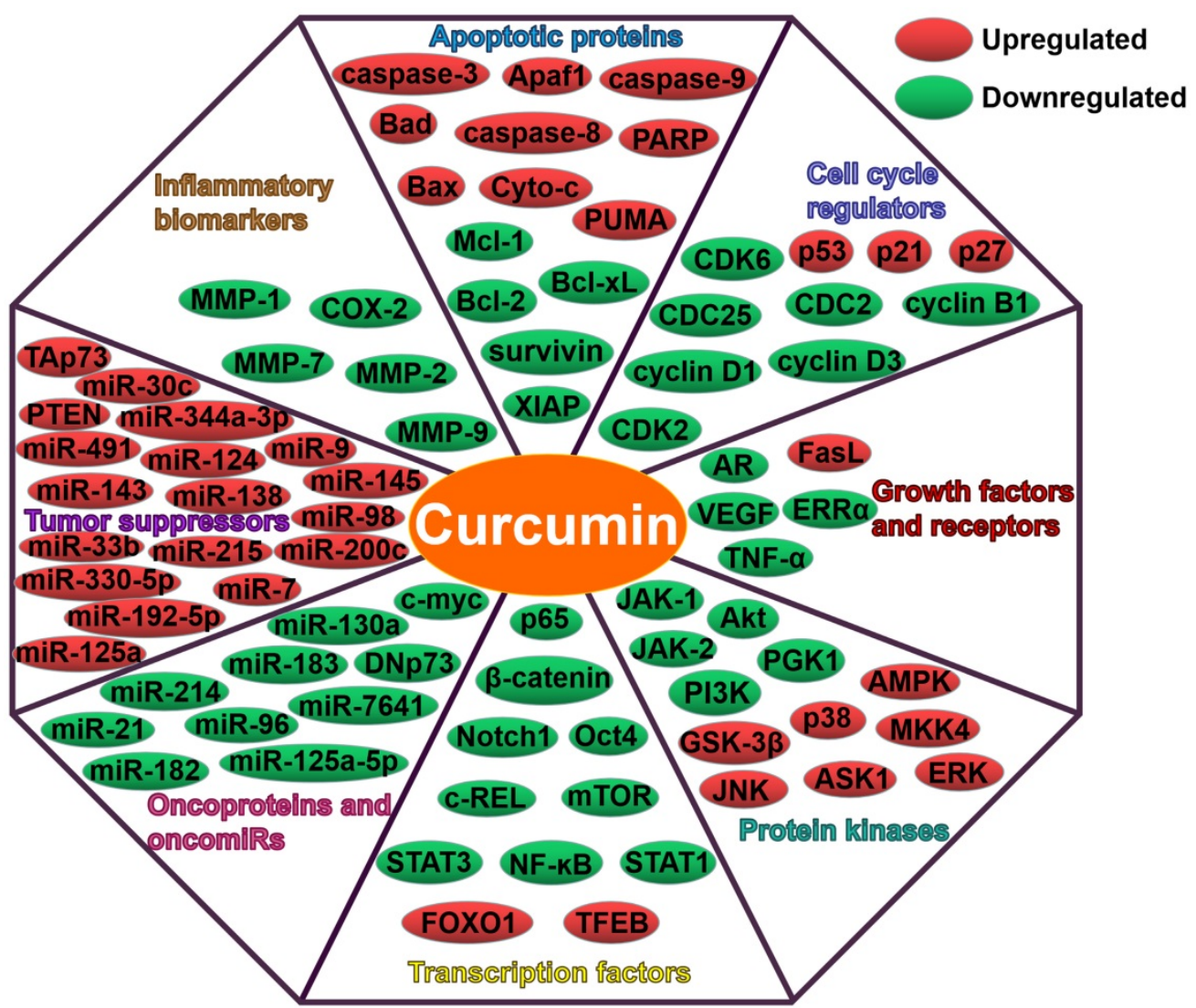

Figure 2. Curcumin suppresses growth, angiogenesis, invasion and metastasis of cancers through regulation of multiple molecular targets. 
Curcumin repressed the proliferation and invasion of human prostate cancer stem cells (HuPCaSCs) [123]. Curcumin upregulated the expression of miR-145 and suppressed that of lncRNA-ROR. Both lncRNA-ROR and Oct4 harbored miR-145 binding sites. Thus, IncRNA-ROR and Oct 4 competed for miR-145 binding. Curcumin decreased lncRNA-ROR expression to effectively increment the abundance of miR-145 in HuPCaSCs, where miR-145 inhibited cancer cell proliferation by reducing Oct 4 expression. Therefore, curcumin prevented the carcinogenesis of HuPCaSCs via ceRNA effects of miR-145 and lncRNA-ROR. The miRNA gene network involved in curcumin-induced metastasis inhibition in lung cancer cells was previously characterized [124]. Six miRNAs (let-7a-3p, miR-1262, miR-1276, miR-330-5p, miR-331-5p and miR-499a-5p) were identified as vital regulators in this network. Among these miRNAs, miR-330-5p showed maximum upregulation in curcumin-treated lung cancer cells. miR-330-5p overexpression obviously restrained lung cancer cell migration, and the effect was similar to that induced by curcumin. Conversely, miR-330-5p downregulation partially reversed the anti-migratory effect of curcumin on lung cancer cells. Therefore, miR-330-5p might be engaged in curcumin-mediated inhibition of lung cancer metastasis. Curcumin was found to significantly sensitize paclitaxel-resistant NSCLC cells to paclitaxel [125]. In terms of mechanism, curcumin decreased the expression of MTA1 by upregulating miR-30c in paclitaxel-resistant NSCLC cells. Curcumin might become a potential adjunct to NSCLC therapy regimens. Curcumin increased the expression of miR-98 and thus downregulated its targets LIN28A, MMP-2 and MMP-9 [126]. Induction of miR-98 by curcumin inhibited lung cancer cell invasion and migration by reducing LIN28A-induced MMP-2 and MMP-9 expression. This study provided new insights into the mechanism by which curcumin inhibited lung cancer growth and invasiveness.

Curcumin could enhance the expression of miR-143 via hypomethylation [127]. miR-143 was able to inhibit autophagy in prostate cancer cells partially through downregulation of autophagy-related gene 2B (ATG2B). Curcumin significantly inhibited radiation-induced autophagy in prostate cancer cells, but promoted radiation-induced cell apoptosis. From these results, curcumin enhanced the sensitivity of prostate cancer cell to radiation via miR-143-mediated autophagy suppression. Phosphoglycerate kinase 1 (PGK1) was found to be associated with the aggressiveness of prostate cancer [128]. Curcumin descended PGK1 expression by upregulating miR-143 [129]. As a result, curcumin inhibited the proliferation and migration of prostate cancer cells. It could be concluded that curcumin exerted anticancer effects on prostate cancer by targeting the miR-143/PGK1 axis. Curcumin could block the EMT process in 5-fluorouracil (5-FU) resistant (5-FUR) CRC cells by upregulating EMT-suppressive miRNAs (miR-34a, miR-101, miR-141, miR-200b, miR-200c and miR-429) [130]. Further study confirmed that upregulation of miR-200c enhanced the expression of E-cadherin, while lowered the expression of EMT-inducing transcription factors (ZEB1 and BMI1). Curcumin also re-sensitized resistant CRC cells to 5-FU by boosting miR-200c-mediated EMT inhibition. To summarize, miR-200c was implicated in the anti-carcinogenic activity of curcumin. These results underlined the therapeutic potential of curcumin through regulation of EMT-suppressive miRNAs.

Curcumin ascended the expression of miR-33b in GC cells and resultantly inhibited that of the miR-33b target, X-linked inhibitor of apoptosis protein (XIAP) [131]. Thus, curcumin exhibited anti-proliferative and pro-apoptotic activities on GC cells. XIAP also served as a target of miR-192-5p/215 [132]. Curcumin increased miR-192-5p/215 expression and thus antagonized XIAP expression in NSCLC cells. The pro-apoptotic effect of curcumin on NSCLC cells relied on miR-192-5p/215 expression. Depletion of estrogen-related receptor a (ERRa) promoted curcumin-mediated growth inhibition in osteosarcoma cells [133]. Curcumin could diminish ERRa expression by upregulating miR-125a. The curcumin/miR-125a/ERRa coupling might be a novel mechanism behind curcumin-induced apoptosis in osteosarcoma cells. Another report also revealed that curcumin remarkably elevated the expression of miR-138 in osteosarcoma cells, thus downregulating its downstream targets Smad4, NF-kB p65 and cyclin D3 [134]. Consequently, curcumin repressed the proliferation and invasion of osteosarcoma cells. Curcumin restrained OSCC cell proliferation by raising miR-9 expression and inhibiting the Wnt/ $\beta$-catenin signaling [135]. Oppositely, inhibition of miR-9 not only weakened the anti-proliferative effect of curcumin on OSCC cells, but also induced the activation of the Wnt/ $\beta$-catenin pathway. These results suggested the potential therapeutic usefulness of curcumin in OSCC management. miR-7 served an important role in modulating PC cell proliferation and apoptosis [136]. Curcumin was reported to inhibit PC progression through upregulation of miR-7 and subsequent downregulation of its downstream target, the histone methyltransferase SET-8. Therefore, curcumin might display great chemotherapeutic effects for PC. 


\section{The clinical benefits of curcumin}

Many clinical studies have addressed the safety and beneficial effects of curcumin in cancer patients. In a phase II clinical trial, 25 patients with advanced PC were administrated $8 \mathrm{~g}$ of curcumin daily until disease progression, with restaging every two months [137]. The results showed that curcumin was well tolerated and displayed biological activity in these patients. Specifically, curcumin reduced the expression of NF-kB, COX-2 and phosphorylated STAT3 in peripheral blood mononuclear cells from patients. A remarkable tumor regression was observed in one patient. Collectively, curcumin might be a potential chemotherapeutic agent against PC. The anticancer activity of curcumin was previously investigated in patients with advanced and metastatic breast cancer [138]. Docetaxel $\left(100 \mathrm{mg} / \mathrm{m}^{2}\right)$ and curcumin ( $6 \mathrm{~g}$ /day) were given for 7 days. A decline in the levels of carcinoembryonic antigen (CEA) and VEGF was observed in 8 patients following docetaxel/curcumin treatment. Therefore, curcumin might be used as an adjuvant to docetaxel for the treatment of breast cancer. The therapeutic potential of curcumin was examined in CRC patients [139]. A total of 126 CRC patients were treated with $1,080 \mathrm{mg}$ of curcumin daily or vehicle for 10-30 days. Curcumin treatment increased the expression of p53 as well as the Bax/Bcl-2 ratio in tumor tissues and thus sped up tumor cell apoptosis in CRC patients. Both monoclonal gammopathy of undetermined significance (MGUS) and smoldering multiple myeloma (SMM) are asymptomatic plasma cell disorders and precursor conditions for progression to multiple myeloma [140]. In a randomized, double-blind placebo-controlled cross-over study, 19 MGUS patients and 17 SMM patients were given 4 $\mathrm{g} /$ day of curcumin or placebo, crossing over at 3 months [141]. Curcumin administration resulted in a decrease in the level of urinary deoxypyridinoline (uDPYD), a marker of bone resorption. Moreover, serum creatinine levels were also reduced in patients treated with curcumin. These results demonstrated that curcumin might possess the potential to mitigate disease progression in patients with MGUS and SMM. Mahammedi et al. [142] conducted a phase II study to assess the efficacy of docetaxel/prednisone in combination with curcumin $(6 \mathrm{~g} /$ day $)$ in 26 patients with castration-resistant prostate cancer. Serum levels of prostate-specific antigen (PSA) were remarkably reduced in $59 \%$ of the patients that received the combination therapy. Meanwhile, tumor objective responses were observed in $40 \%$ of the patients. These findings suggested the clinical feasibility of docetaxel/prednisone in combination with curcumin in the treatment of castration-resistant prostate cancer.
In a recent study, 44 patients with advanced PC were given gemcitabine $\left(100 \mathrm{mg} / \mathrm{m}^{2}\right)$ and $2 \mathrm{~g} /$ day of Meriva $^{\circledR}$ (containing $\sim 667 \mathrm{mg}$ phytosome complex of curcumin) [143]. The overall survival of patients that received gemcitabine/Meriva ${ }^{\circledR}$ (10.2 months) was higher than that of patients treated with gemcitabine alone (5.7 months) [144]. The complementary administration of phytosome complex of curcumin might enhance the anticancer efficiency of gemcitabine. From the results of these clinical trials, curcumin displays therapeutic potential against different types of human cancers. However, more well-designed studies in larger cohorts are required to confirm the safety and efficacy of curcumin in cancer patients.

\section{Conclusions and Future Directions}

Curcumin is a natural phenolic compound extracted from the dietary spice turmeric. The safety, non-toxicity and tolerability of curcumin have been well established by clinical trials [138, 145, 146]. Curcumin has been found to possess antioxidant, anti-microbial and anti-inflammatory properties. More importantly, it exhibits anti-carcinogenic activity against a wide variety of human cancers. The anticancer mechanisms of curcumin involve regulation of numerous signaling pathways. Multiple lines of evidence demonstrate that curcumin can modulate Wnt/ $\beta$-catenin, PI3K/Akt, JAK/STAT, MAPK, p53 and NF-KB signaling pathways in cancer cells. Moreover, curcumin also orchestrate the apoptotic and autophagic pathways. It is envisioned that curcumin may prevent the development of chemoresistance owing to its multi-targeting activity in cancer. However, further work is needed to deeply illuminate the complex regulatory networks that contribute to the anticancer actions of curcumin. Moreover, the influences of curcumin on cellular signaling pathways remain to be validated in vivo. The consequences of curcumin-mediated regulation of cellular signaling cascades in normal cells merit further exploration. According to their function in carcinogenesis, miRNAs can be classified into oncogenic miRNAs and tumor-suppressive miRNAs [147]. Curcumin is able to control the expression and activity of oncogenic and tumor-suppressive miRNAs. miRNAs usually target multiple genes and consequently affect various signaling pathways. This may explain why curcumin exerts broad regulatory effects on cellular signaling cascades in cancer. It is intriguing to identify common curcumin-responsive miRNAs in different types of cancers and further disclose their roles in curcumin-mediated tumor suppression. Curcumin was reported to regulate long non-coding RNAs (lncRNAs) in cancer [123]. 
Aberrantly expressed lncRNAs may represent potential targets for cancer treatment [148]. At present, the research on the regulatory role of curcumin in cancer-associated lncRNA expression is still in its early stages. Further studies are needed to systematically discover and characterize cancer-associated lncRNAs regulated by curcumin. The high-throughput sequencing technology can be exploited to identify novel lncRNAs critical for the anticancer actions of curcumin. An in-depth investigation into the impact of curcumin on lncRNA expression will contribute to elucidating the complex miRNA-mRNA-lnRNA interaction networks involved in curcumin-mediated tumor suppression. The detailed mechanisms by which curcumin regulate ncRNAs are demanded to be further explored. The effects of curcumin on the subcellular localization and function of ncRNAs await to be elucidated. Additional studies are necessary to determine if curcumin can target ncRNAs in non-tumorous cells.

Although the cancer chemotherapeutic effects of curcumin have been verified in multiple types of cancer cells, its efficacy is very limited in both pre-clinical and clinical studies. This may be attributed to its low water solubility, rapid metabolism and inefficient absorption. Thus, it is imperative to improve the bioavailability and intracellular accumulation of curcumin in vivo. Several approaches could be applied to overcome these limitations. The utilization of adjuvant like piperine, structural analogues, and the development of delivery vehicles (e.g., liposomes and nanoparticles) could improve the bioavailability and efficacy of curcumin [149]. Strategies aimed at improving the efficacy of curcumin may increase its toxicity. Further clinical studies are required to evaluate the safety and anticancer efficiency of these highly bioavailable forms of curcumin in humans. In addition, the direct relationship between their bioavailability and effectiveness is warranted to be further studied. Notably, most of delivery vehicles lack specificity for particular cancer tissues. The delivery systems need to be improved for targeted transfer of curcumin to cancer cells, contributing to better clinical outcomes. Specifically, tumor-specific curcumin delivery increases its local concentration in the target site, thus giving rise to higher anticancer efficacy. The therapeutic efficacy of curcumin in combination with conventional anticancer drugs has been proven in several clinical trials. Curcumin could be a prospective adjunct to traditional chemotherapy regimens. Therefore, the synergistic effects of curcumin with current therapeutic approaches in cancer should be deemed as a subject of further research, which would facilitate the development of effective anticancer therapeutics. More well-controlled clinical trials in large cohorts are undoubtedly essential to determine the safety, tolerability and therapeutic effectiveness of curcumin in conjunction with existing anticancer therapeutics.

\section{Acknowledgements}

This work was financially supported by the National Natural Science Foundation of China (81701991) and Applied Basic Research Programs of Qingdao, China (17-1-1-59-jch).

\section{Competing Interests}

The authors have declared that no competing interest exists.

\section{References}

1. Shanmugam MK, Rane G, Kanchi MM, Arfuso F, Chinnathambi A, Zayed ME, et al. The multifaceted role of curcumin in cancer prevention and treatment. Molecules. 2015; 20: 2728-69.

2. Hanahan D, Weinberg RA. Hallmarks of cancer: the next generation. Cell. 2011; 144: 646-74.

3. Torre LA, Siegel RL, Ward EM, Jemal A. Global Cancer Incidence and Mortality Rates and Trends--An Update. Cancer epidemiology, biomarkers \& prevention : a publication of the American Association for Cancer Research, cosponsored by the American Society of Preventive Oncology. 2016; 25: 16-27.

4. Abotaleb M, Kubatka P, Caprnda M, Varghese E, Zolakova B, Zubor P, et al. Chemotherapeutic agents for the treatment of metastatic breast cancer: An update. Biomedicine \& Pharmacotherapy. 2018; 101: 458-77.

5. Achkar IW, Abdulrahman N, Al-Sulaiti H, Joseph JM, Uddin S, Mraiche F. Cisplatin based therapy: the role of the mitogen activated protein kinase signaling pathway. Journal of translational medicine. 2018; 16: 96.

6. Sosa Iglesias V, Giuranno L, Dubois LJ, Theys J, Vooijs M. Drug Resistance in Non-Small Cell Lung Cancer: A Potential for NOTCH Targeting? Frontiers in oncology. 2018; 8: 267.

7. Rashidi B, Malekzadeh M, Goodarzi M, Masoudifar A, Mirzaei H. Green tea and its anti-angiogenesis effects. Biomedicine \& Pharmacotherapy. 2017; 89: 949-56.

8. Pavan AR, Silva GD, Jornada DH, Chiba DE, Fernandes GF, Man Chin C, et al. Unraveling the Anticancer Effect of Curcumin and Resveratrol. Nutrients. 2016; 8: 628

9. Goyal S, Gupta N, Chatterjee S, Nimesh S. Natural Plant Extracts as Potential Therapeutic Agents for the Treatment of Cancer. Current topics in medicinal chemistry. 2017; 17: 96-106.

10. Teiten MH, Eifes S, Dicato M, Diederich M. Curcumin-the paradigm of a multi-target natural compound with applications in cancer prevention and treatment. Toxins. 2010; 2: 128-62.

11. Maheshwari RK, Singh AK, Gaddipati J, Srimal RC. Multiple biological activities of curcumin: a short review. Life sciences. 2006; 78: 2081-7.

12. Kocaadam B, Sanlier N. Curcumin, an active component of turmeric (Curcuma longa), and its effects on health. Critical reviews in food science and nutrition. 2017; 57: 2889-95.

13. Singh $M$, Singh N. Molecular mechanism of curcumin induced cytotoxicity in human cervical carcinoma cells. Molecular and cellular biochemistry. 2009; 325: 107-19.

14. Singh M, Singh N. Curcumin counteracts the proliferative effect of estradiol and induces apoptosis in cervical cancer cells. Molecular and cellular biochemistry. 2011; 347: 1-11.

15. Aggarwal BB, Yuan W, Li S, Gupta SC. Curcumin-free turmeric exhibits anti-inflammatory and anticancer activities: Identification of novel components of turmeric. Molecular nutrition \& food research. 2013; 57: 1529-42

16. Brouet I, Ohshima H. Curcumin, an anti-tumour promoter and anti-inflammatory agent, inhibits induction of nitric oxide synthase in activated macrophages. Biochemical and biophysical research communications. 1995; 206: 533-40.

17. Ak T, Gulcin I. Antioxidant and radical scavenging properties of curcumin. Chemico-biological interactions. 2008; 174: 27-37.

18. Rahmani AH, Alsahli MA, Aly SM, Khan MA, Aldebasi YH. Role of Curcumin in Disease Prevention and Treatment. Advanced biomedical research. 2018; 7:

19. Mokhtari-Zaer A, Marefati N, Atkin SL, Butler AE, Sahebkar A. The protective role of curcumin in myocardial ischemia-reperfusion injury. Journal of cellular physiology. 2018; 234: 214-22 
20. Panda AK, Chakraborty D, Sarkar I, Khan T, Sa G. New insights into therapeutic activity and anticancer properties of curcumin. Journal of experimental pharmacology. 2017; 9: 31-45.

21. Kunnumakkara AB, Bordoloi D, Harsha C, Banik K, Gupta SC, Aggarwal BB. Curcumin mediates anticancer effects by modulating multiple cell signaling pathways. Clinical science. 2017; 131: 1781-99.

22. Momtazi AA, Shahabipour F, Khatibi S, Johnston TP, Pirro M, Sahebkar A. Curcumin as a MicroRNA Regulator in Cancer: A Review. Reviews of physiology, biochemistry and pharmacology. 2016; 171: 1-38.

23. Hesari A, Azizian M, Sheikh A, Nesaei A, Sanaei S, Mahinparvar N, et al. Chemopreventive and therapeutic potential of curcumin in esophageal cancer: Current and future status. International journal of cancer. 2019 144: 1215-26.

24. Barati N, Momtazi-Borojeni AA, Majeed M, Sahebkar A. Potential therapeutic effects of curcumin in gastric cancer. Journal of cellular physiology. 2019; 234: 2317-28.

25. Jalili-Nik M, Soltani A, Moussavi S, Ghayour-Mobarhan M, Ferns GA, Hassanian SM, et al. Current status and future prospective of Curcumin as a potential therapeutic agent in the treatment of colorectal cancer. Journal of cellular physiology. 2018; 233: 6337-45.

26. Kunnumakkara AB, Anand P, Aggarwal BB. Curcumin inhibits proliferation, invasion, angiogenesis and metastasis of different cancers through interaction with multiple cell signaling proteins. Cancer letters. 2008; 269: 199-225.

27. Pai SG, Carneiro BA, Mota JM, Costa R, Leite CA, Barroso-Sousa R, et al. Wnt/beta-catenin pathway: modulating anticancer immune response. Journal of hematology \& oncology. 2017; 10: 101.

28. Shang S, Hua F, Hu ZW. The regulation of beta-catenin activity and function in cancer: therapeutic opportunities. Oncotarget. 2017; 8: 33972-89.

29. Hu P, Ke C, Guo X, Ren P, Tong $Y$, Luo $S$, et al. Both glypican-3/Wnt/beta-catenin signaling pathway and autophagy contributed to the inhibitory effect of curcumin on hepatocellular carcinoma. Digestive and liver disease : official journal of the Italian Society of Gastroenterology and the Italian Association for the Study of the Liver. 2019; 51: 120-6.

30. Xu MX, Zhao L, Deng C, Yang L, Wang Y, Guo T, et al. Curcumin suppresses proliferation and induces apoptosis of human hepatocellular carcinoma cells via the wnt signaling pathway. International journal of oncology. 2013; 43: 1951-9.

31. Kim HJ, Park SY, Park OJ, Kim YM. Curcumin suppresses migration and proliferation of Hep3B hepatocarcinoma cells through inhibition of the Wnt signaling pathway. Molecular medicine reports. 2013; 8: 282-6.

32. Li X, Wang X, Xie C, Zhu J, Meng Y, Chen Y, et al. Sonic hedgehog and Wnt/beta-catenin pathways mediate curcumin inhibition of breast cancer stem cells. Anti-cancer drugs. 2018; 29: 208-15.

33. Zheng R, Deng Q, Liu Y, Zhao P. Curcumin Inhibits Gastric Carcinoma Cell Growth and Induces Apoptosis by Suppressing the Wnt/beta-Catenin Signaling Pathway. Medical science monitor : international medical journal of experimental and clinical research. 2017; 23: 163-71.

34. Feng W, Yang CX, Zhang L, Fang Y, Yan M. Curcumin promotes the apoptosis of human endometrial carcinoma cells by downregulating the expression of androgen receptor through Wnt signal pathway. European journal of gynaecological oncology. 2014; 35: 718-23.

35. Wang JY, Wang X, Wang XI, Zheng BZ, Wang Y, Wang X, et al. Curcumin inhibits the growth via Wnt/beta-catenin pathway in non-small-cell lung cancer cells. European review for medical and pharmacological sciences. 2018; 22: 7492-9.

36. Dou H, Shen R, Tao J, Huang L, Shi H, Chen H, et al. Curcumin Suppresses the Colon Cancer Proliferation by Inhibiting Wnt/beta-Catenin Pathways via miR-130a. Frontiers in pharmacology. 2017; 8: 877.

37. He MS, Li Y, Zhang L, Li LJ, Shen Y, Lin L, et al. Curcumin suppresses cell proliferation through inhibition of the Wnt/beta-catenin signaling pathway in medulloblastoma. Oncology reports. 2014; 32: 173-80.

38. Thiery JP. Epithelial-mesenchymal transitions in development and pathologies. Current opinion in cell biology. 2003; 15: 740-6.

39. Gonzalez DM, Medici D. Signaling mechanisms of the epithelial-mesenchymal transition. Science signaling. 2014; 7: re8.

40. Zhang $\mathrm{Z}$, Chen $\mathrm{H}, \mathrm{Xu} \mathrm{C}$, Song L, Huang L, Lai $\mathrm{Y}$, et al. Curcumin inhibits tumor epithelialmesenchymal transition by downregulating the Wnt signaling pathway and upregulating NKD2 expression in colon cancer cells. Oncology reports. 2016; 35: 2615-23.

41. Wang H, Fan L, Wei J, Weng Y, Zhou L, Shi Y, et al. Akt mediates metastasis-associated gene 1 (MTA1) regulating the expression of E-cadherin and promoting the invasiveness of prostate cancer cells. PloS one. 2012; 7: e46888.

42. Lu Y, Wei C, Xi Z. Curcumin suppresses proliferation and invasion in non-small cell lung cancer by modulation of MTA1-mediated Wnt/beta-catenin pathway. In vitro cellular \& developmental biology Animal. 2014; 50: 840-50.

43. Yu JS, Cui W. Proliferation, survival and metabolism: the role of $\mathrm{PI} 3 \mathrm{~K} / \mathrm{AKT} / \mathrm{mTOR}$ signalling in pluripotency and cell fate determination. Development. 2016; 143: 3050-60.

44. Luo J, Manning BD, Cantley LC. Targeting the PI3K-Akt pathway in human cancer: rationale and promise. Cancer cell. 2003; 4: 257-62.

45. Hu S, Xu Y, Meng L, Huang L, Sun H. Curcumin inhibits proliferation and promotes apoptosis of breast cancer cells. Experimental and therapeutic medicine. 2018; 16: 1266-72
46. Akkoc Y, Berrak O, Arisan ED, Obakan P, Coker-Gurkan A, Palavan-Unsal N. Inhibition of PI3K signaling triggered apoptotic potential of curcumin which is hindered by $\mathrm{Bcl}-2$ through activation of autophagy in MCF-7 cells. Biomedicine \& Pharmacotherapy. 2015; 71: 161-71.

47. Wang J, Wang C, Bu G. Curcumin inhibits the growth of liver cancer stem cells through the phosphatidylinositol 3-kinase/protein kinase B/mammalian target of rapamycin signaling pathway. Experimental and therapeutic medicine. 2018; 15: 3650-8.

48. Liu F, Gao S, Yang Y, Zhao X, Fan Y, Ma W, et al. Antitumor activity of curcumin by modulation of apoptosis and autophagy in human lung cancer A549 cells through inhibiting PI3K/Akt/mTOR pathway. Oncology reports. 2018; 39: 1523-31.

49. Jin H, Qiao F, Wang Y, Xu Y, Shang Y. Curcumin inhibits cell proliferation and induces apoptosis of human non-small cell lung cancer cells through the upregulation of miR-192-5p and suppression of PI3K/Akt signaling pathway. Oncology reports. 2015; 34: 2782-9.

50. Zhang H, Xu W, Li B, Zhang K, Wu Y, Xu H, et al. Curcumin Promotes Cell Cycle Arrest and Inhibits Survival of Human Renal Cancer Cells by Negative Modulation of the PI3K/AKT Signaling Pathway. Cell biochemistry and biophysics. 2015; 73: 681-6.

51. Yu Z, Wan Y, Liu Y, Yang J, Li L, Zhang W. Curcumin induced apoptosis via PI3K/Akt-signalling pathways in SKOV3 cells. Pharmaceutical biology. 2016; 54: 2026-32.

52. Zhao Z, Li C, Xi H, Gao Y, Xu D. Curcumin induces apoptosis in pancreatic cancer cells through the induction of forkhead box $\mathrm{O} 1$ and inhibition of the PI3K/Akt pathway. Molecular medicine reports. 2015; 12: 5415-22.

53. Qiao Q, Jiang Y, Li G. Inhibition of the PI3K/AKT-NF-kappaB pathway with curcumin enhanced radiation-induced apoptosis in human Burkitt's lymphoma. Journal of pharmacological sciences. 2013; 121: 247-56.

54. Li W, Jiang Z, Xiao X, Wang Z, Wu Z, Ma Q, et al. Curcumin inhibits superoxide dismutase-induced epithelial-to-mesenchymal transition via the PI3K/Akt/NF-kappaB pathway in pancreatic cancer cells. International journal of oncology. 2018; doi: 10.3892/ijo.2018.4295.

55. Xu X, Qin J, Liu W. Curcumin inhibits the invasion of thyroid cancer cells via down-regulation of PI3K/Akt signaling pathway. Gene. 2014; 546: 226-32.

56. Jiang QG, Li TY, Liu DN, Zhang HT. PI3K/Akt pathway involving into apoptosis and invasion in human colon cancer cells LoVo. Molecular biology reports. 2014; 41: 3359-67.

57. Morris R, Kershaw NJ, Babon JJ. The molecular details of cytokine signaling via the JAK/STAT pathway. Protein science : a publication of the Protein Society. 2018; 27: 1984-2009.

58. Villarino AV, Kanno Y, O'Shea JJ. Mechanisms and consequences of Jak-STAT signaling in the immune system. Nature immunology. 2017; 18: 374-84

59. Koppikar P, Lui VW, Man D, Xi S, Chai RL, Nelson E, et al. Constitutive activation of signal transducer and activator of transcription 5 contributes to tumor growth, epithelial-mesenchymal transition, and resistance to epidermal growth factor receptor targeting. Clinical cancer research : an official journal of the American Association for Cancer Research. 2008; 14: 7682-90.

60. Li Y, Sun W, Han N, Zou Y, Yin D. Curcumin inhibits proliferation, migration, invasion and promotes apoptosis of retinoblastoma cell lines through modulation of miR-99a and JAK/STAT pathway. BMC cancer. 2018; 18: 1230.

61. Xu X, Zhu Y. Curcumin inhibits human non-small cell lung cancer xenografts by targeting STAT3 pathway. American journal of translational research. 2017; 9: 3633-41.

62. Hu A, Huang JJ, Jin XJ, Li JP, Tang YJ, Huang XF, et al. Curcumin suppresses invasiveness and vasculogenic mimicry of squamous cell carcinoma of the larynx through the inhibition of JAK-2/STAT-3 signaling pathway. American journal of cancer research. 2015; 5: 278-88.

63. Yang CL, Liu YY, Ma YG, Xue YX, Liu DG, Ren Y, et al. Curcumin blocks small cell lung cancer cells migration, invasion, angiogenesis, cell cycle and neoplasia through Janus kinase-STAT3 signalling pathway. PloS one. 2012; 7: e37960.

64. Arthur JS, Ley SC. Mitogen-activated protein kinases in innate immunity. Nature reviews Immunology. 2013; 13: 679-92.

65. Dong C, Davis RJ, Flavell RA. MAP kinases in the immune response. Annual review of immunology. 2002; 20: 55-72.

66. Shi JH, Sun SC. Tumor Necrosis Factor Receptor-Associated Factor Regulation of Nuclear Factor kappaB and Mitogen-Activated Protein Kinase Pathways. Frontiers in immunology. 2018; 9: 1849.

67. Lim W, Jeong M, Bazer FW, Song G. Curcumin Suppresses Proliferation and Migration and Induces Apoptosis on Human Placental Choriocarcinoma Cells via ERK1/2 and SAPK/JNK MAPK Signaling Pathways. Biology of reproduction. 2016; 95: 83 .

68. Yu X, Zhong J, Yan L, Li J, Wang H, Wen Y, et al. Curcumin exerts antitumor effects in retinoblastoma cells by regulating the JNK and p38 MAPK pathways. International journal of molecular medicine. 2016; 38: 861-8.

69. Yao Q, Lin M, Wang Y, Lai Y, Hu J, Fu T, et al. Curcumin induces the apoptosis of A549 cells via oxidative stress and MAPK signaling pathways. International journal of molecular medicine. 2015; 36: 1118-26.

70. Zhu GH, Dai HP, Shen Q, Ji O, Zhang Q, Zhai YL. Curcumin induces apoptosis and suppresses invasion through MAPK and MMP signaling in human monocytic leukemia SHI-1 cells. Pharmaceutical biology. 2016; 54: 1303-11.

71. Zhang Y, Dube C, Gibert M, Jr., Cruickshanks N, Wang B, Coughlan M, et al. The p53 Pathway in Glioblastoma. Cancers. 2018; 10: 297. 
72. Gong $\mathrm{H}$, Cao $\mathrm{Y}$, Han $\mathrm{G}$, Zhang $\mathrm{Y}$, You $\mathrm{Q}$ Wang $\mathrm{Y}$, et al. p53/microRNA-374b/AKT1 regulates colorectal cancer cell apoptosis in response to DNA damage. International journal of oncology. 2017; 50: 1785-91.

73. Su P, Wang F, Qi B, Wang T, Zhang S. P53 Regulation-Association Long Non-Coding RNA (LncRNA PRAL) Inhibits Cell Proliferation by Regulation of P53 in Human Lung Cancer. Medical science monitor : international medical journal of experimental and clinical research. 2017; 23: 1751-8.

74. Fu H, Wang C, Yang D, Wei Z, Xu J, Hu Z, et al. Curcumin regulates proliferation, autophagy, and apoptosis in gastric cancer cells by affecting PI3K and P53 signaling. Journal of cellular physiology. 2018; 233: 4634-42.

75. Lee AY, Fan CC, Chen YA, Cheng CW, Sung YJ, Hsu CP, et al. Curcumin Inhibits Invasiveness and Epithelial-Mesenchymal Transition in Oral Squamous Cell Carcinoma Through Reducing Matrix Metalloproteinase 2, 9 and Modulating p53-E-Cadherin Pathway. Integrative cancer therapies. 2015; 14: 484-90.

76. Li W, Wang Y, Song Y, Xu L, Zhao J, Fang B. A preliminary study of the effect of curcumin on the expression of p53 protein in a human multiple myeloma cell line. Oncology letters. 2015; 9: 1719-24.

77. Dang YP, Yuan XY, Tian R, Li DG, Liu W. Curcumin improves the paclitaxel-induced apoptosis of HPV-positive human cervical cancer cells via the NF-kappaB-p53-caspase-3 pathway. Experimental and therapeutic medicine. 2015; 9: 1470-6.

78. Vageli DP, Doukas SG, Spock T, Sasaki CT. Curcumin prevents the bile reflux-induced NF-kappaB-related mRNA oncogenic phenotype, in human hypopharyngeal cells. Journal of cellular and molecular medicine. 2018; 22: 4209-20.

79. Liu G, Wang Y, Li M. Curcumin sensitized the antitumour effects of irradiation in promoting apoptosis of oesophageal squamous-cell carcinoma through NF-kappaB signalling pathway. The Journal of pharmacy and pharmacology. 2018; 70: 1340-8

80. Coker-Gurkan A, Celik M, Ugur M, Arisan ED, Obakan-Yerlikaya P, Durdu $\mathrm{ZB}$, et al. Curcumin inhibits autocrine growth hormone-mediated invasion and metastasis by targeting NF-kappaB signaling and polyamine metabolism in breast cancer cells. Amino acids. 2018; 50: 1045-69.

81. Mortezaee K, Salehi E, Mirtavoos-Mahyari H, Motevaseli E, Najafi M, Farhood B, et al. Mechanisms of apoptosis modulation by curcumin: Implications for cancer therapy. Journal of cellular physiology. 2019; doi: 10.1002/jcp.28122.

82. Shankar S, Srivastava RK. Involvement of Bcl-2 family members, phosphatidylinositol 3'-kinase/AKT and mitochondrial p53 in curcumin (diferulolylmethane)-induced apoptosis in prostate cancer. International journal of oncology. 2007; 30: 905-18.

83. Zhu Y, Bu S. Curcumin Induces Autophagy, Apoptosis, and Cell Cycle Arrest in Human Pancreatic Cancer Cells. Evidence-based complementary and alternative medicine : eCAM. 2017; 2017: 5787218.

84. Zhang Y, Tu L, Zhou X, Li B. Curcumin-Mediated Induction of Apoptosis in Human Glioma CHME Cells. Medical science monitor basic research. 2018; 24: 216-24.

85. Li W, Zhou Y, Yang J, Li H, Zhang H, Zheng P. Curcumin induces apoptotic cell death and protective autophagy in human gastric cancer cells. Oncology reports. 2017; 37: 3459-66

86. Liang T, Zhang $X$, Xue $W$, Zhao S, Zhang X, Pei J. Curcumin induced human gastric cancer BGC-823 cells apoptosis by ROS-mediated ASK1-MKK4-JNK stress signaling pathway. International journal of molecular sciences. 2014; 15 : 15754-65.

87. Wang J, Xie H, Gao F, Zhao T, Yang H, Kang B. Curcumin induces apoptosis in p53-null Hep3B cells through a TAp73/DNp73-dependent pathway. Tumour biology : the journal of the International Society for Oncodevelopmental Biology and Medicine. 2016; 37: 4203-12.

88. Urist M, Tanaka T, Poyurovsky MV, Prives C. p73 induction after DNA damage is regulated by checkpoint kinases Chk1 and Chk2. Genes \& development. 2004; 18: 3041-54

89. Zaika E, Wei J, Yin D, Andl C, Moll U, El-Rifai W, et al. p73 protein regulates DNA damage repair. FASEB journal : official publication of the Federation of American Societies for Experimental Biology. 2011; 25: 4406-14.

90. Ferru A, Denis S, Guilhot J, Gibelin H, Tourani JM, Kraimps JL, et al. Expression of TAp73 and DeltaNp73 isoform transcripts in thyroid tumours. European journal of surgical oncology : the journal of the European Society of Surgical Oncology and the British Association of Surgical Oncology. 2006; 32: 228-30

91. Lo Iacono M, Monica V, Saviozzi S, Ceppi P, Bracco E, Papotti M, et al. p63 and p73 isoform expression in non-small cell lung cancer and corresponding morphological normal lung tissue. Journal of thoracic oncology : official publication of the International Association for the Study of Lung Cancer. 2011; 6: 473-81

92. Zheng R, You Z, Jia J, Lin S, Han S, Liu A, et al. Curcumin enhances the antitumor effect of ABT-737 via activation of the ROS-ASK1-JNK pathway in hepatocellular carcinoma cells. Molecular medicine reports. 2016; 13: 1570-6.

93. Liu ZC, Yang ZX, Zhou JS, Zhang HT, Huang QK, Dang LL, et al. Curcumin regulates hepatoma cell proliferation and apoptosis through the Notch signaling pathway. International journal of clinical and experimental medicine. 2014; 7: 714-8.

94. Li Y, Zhang S, Geng JX, Hu XY. Curcumin inhibits human non-small cell lung cancer A549 cell proliferation through regulation of Bcl-2/Bax and cytochrome C. Asian Pacific journal of cancer prevention : APJCP. 2013; 14: 4599-602.
95. Baharuddin P, Satar N, Fakiruddin KS, Zakaria N, Lim MN, Yusoff NM, et al. Curcumin improves the efficacy of cisplatin by targeting cancer stem-like cells through p21 and cyclin D1-mediated tumour cell inhibition in non-small cell lung cancer cell lines. Oncology reports. 2016; 35: 13-25.

96. $\mathrm{Hu}$ A, Huang JJ, Li RL, Lu ZY, Duan JL, Xu WH, et al. Curcumin as therapeutics for the treatment of head and neck squamous cell carcinoma by activating SIRT1. Scientific reports. 2015; 5: 13429.

97. Koprowski S, Sokolowski K, Kunnimalaiyaan S, Gamblin TC, Kunnimalaiyaan M. Curcumin-mediated regulation of Notch1/hairy and enhancer of split-1/survivin: molecular targeting in cholangiocarcinoma. The Journal of surgical research. 2015; 198: 434-40.

98. Yun JH, Park YG, Lee KM, Kim J, Nho CW. Curcumin induces apoptotic cell death via Oct4 inhibition and GSK-3beta activation in NCCIT cells. Molecular nutrition \& food research. 2015; 59: 1053-62.

99. Jiang AJ, Jiang G, Li LT, Zheng JN. Curcumin induces apoptosis through mitochondrial pathway and caspases activation in human melanoma cells. Molecular biology reports. 2015; 42: 267-75.

100. Picone P, Nuzzo D, Caruana L, Messina E, Scafidi V, Di Carlo M. Curcumin induces apoptosis in human neuroblastoma cells via inhibition of AKT and Foxo3a nuclear translocation. Free radical research. 2014; 48: 1397-408.

101. Gopal PK, Paul M, Paul S. Curcumin induces caspase mediated apoptosis in JURKAT cells by disrupting the redox balance. Asian Pacific journal of cancer prevention : APJCP. 2014; 15: 93-100.

102. Chang Z, Xing J, Yu X. Curcumin induces osteosarcoma MG63 cells apoptosis via ROS/Cyto-C/Caspase-3 pathway. Tumour biology : the journal of the International Society for Oncodevelopmental Biology and Medicine. 2014; 35: 753-8.

103. Zhu J, Zhao B, Xiong P, Wang C, Zhang J, Tian X, et al. Curcumin Induces Autophagy via Inhibition of Yes-Associated Protein (YAP) in Human Colon Cancer Cells. Medical science monitor : international medical journal of experimental and clinical research. 2018; 24: 7035-42.

104. Matarrese P, Garofalo T, Manganelli V, Gambardella L, Marconi M, Grasso M, et al. Evidence for the involvement of GD3 ganglioside in autophagosome formation and maturation. Autophagy. 2014; 10: 750-65.

105. Lee M, Kim KS, Fukushi A, Kim DH, Kim CH, Lee YC. Transcriptional Activation of Human GD3 Synthase (hST8Sia I) Gene in Curcumin-Induced Autophagy in A549 Human Lung Carcinoma Cells. International journal of molecular sciences. 2018; 19: 1943.

106. Guo Y, Shan QQ, Gong PY, Wang SC. The autophagy induced by curcumin via MEK/ERK pathway plays an early anti-leukemia role in human Philadelphia chromosome-positive acute lymphoblastic leukemia SUP-B15 cells. Journal of cancer research and therapeutics. 2018; 14: S125-S31.

107. Deng Q, Liang L, Liu Q, Duan W, Jiang Y, Zhang L. Autophagy is a major mechanism for the dual effects of curcumin on renal cell carcinoma cells. European journal of pharmacology. 2018; 826: 24-30.

108. Zhang Y, Chen P, Hong H, Wang L, Zhou Y, Lang Y. JNK pathway mediates curcumin-induced apoptosis and autophagy in osteosarcoma MG63 cells. Experimental and therapeutic medicine. 2017; 14: 593-9.

109. Settembre C, Di Malta C, Polito VA, Garcia Arencibia M, Vetrini F, Erdin S, et al. TFEB links autophagy to lysosomal biogenesis. Science. 2011; 332: 1429-33.

110. Zhang J, Wang J, Xu J, Lu Y, Jiang J, Wang L, et al. Curcumin targets the TFEB-lysosome pathway for induction of autophagy. Oncotarget. 2016; 7: 75659-71.

111. Guan F, Ding Y, Zhang Y, Zhou Y, Li M, Wang C. Curcumin Suppresses Proliferation and Migration of MDA-MB-231 Breast Cancer Cells through Autophagy-Dependent Akt Degradation. PloS one. 2016; 11: e0146553.

112. Zhao G, Han X, Zheng S, Li Z, Sha Y, Ni J, et al. Curcumin induces autophagy, inhibits proliferation and invasion by downregulating AKT/mTOR signaling pathway in human melanoma cells. Oncology reports. 2016; 35: 1065-74.

113. Norouzi S, Majeed M, Pirro M, Generali D, Sahebkar A. Curcumin as an Adjunct Therapy and microRNA Modulator in Breast Cancer. Current pharmaceutical design. 2018; 24: 171-7.

114. Ma Y, Liang AJ, Fan YP, Huang YR, Zhao XM, Sun Y, et al. Dysregulation and functional roles of miR-183-96-182 cluster in cancer cell proliferation, invasion and metastasis. Oncotarget. 2016; 7: 42805-25.

115. Coker-Gurkan A, Bulut D, Genc R, Arisan ED, Obakan-Yerlikaya P, Palavan-Unsal N. Curcumin prevented human autocrine growth hormone (GH) signaling mediated NF-kappaB activation and miR-183-96-182 cluster stimulated epithelial mesenchymal transition in T47D breast cancer cells. Molecular biology reports. 2018; 46: 355-69.

116. Wang K, Tan SL, Lu Q, Xu R, Cao J, Wu SQ, et al. Curcumin Suppresses microRNA-7641-Mediated Regulation of p16 Expression in Bladder Cancer. The American journal of Chinese medicine. 2018; 46: 1357-68.

117. Zhang J, Liu J, Xu X, Li L. Curcumin suppresses cisplatin resistance development partly via modulating extracellular vesicle-mediated transfer of MEG3 and miR-214 in ovarian cancer. Cancer chemotherapy and pharmacology. 2017; 79: 479-87.

118. Taverna S, Giallombardo M, Pucci M, Flugy A, Manno M, Raccosta S, et al. Curcumin inhibits in vitro and in vivo chronic myelogenous leukemia cells growth: a possible role for exosomal disposal of miR-21. Oncotarget. 2015; 6: 21918-33.

119. Gao W, Chan JY, Wong TS. Curcumin exerts inhibitory effects on undifferentiated nasopharyngeal carcinoma by inhibiting the expression of miR-125a-5p. Clinical science. 2014; 127: 571-9. 
120. Sohn EJ, Bak KM, Nam YK, Park HT. Upregulation of microRNA 344a-3p is involved in curcumin induced apoptosis in RT4 schwannoma cells. Cancer cell international. 2018; 18: 199.

121. Li B, Shi C, Li B, Zhao JM, Wang L. The effects of Curcumin on HCT-116 cells proliferation and apoptosis via the miR-491/PEG10 pathway. Journal of cellular biochemistry. 2018; 119: 3091-8.

122. Zhao J, Pan $Y$, Li X, Zhang X, Xue $Y$, Wang T, et al. Dihydroartemisinin and Curcumin Synergistically Induce Apoptosis in SKOV3 Cells Via Upregulation of MiR-124 Targeting Midkine. Cellular physiology and biochemistry : international journal of experimental cellular physiology, biochemistry, and pharmacology. 2017; 43: 589-601.

123. Liu T, Chi H, Chen J, Chen C, Huang Y, Xi H, et al. Curcumin suppresses proliferation and in vitro invasion of human prostate cancer stem cells by ceRNA effect of miR-145 and lncRNA-ROR. Gene. 2017; 631: 29-38.

124. Zhan JW, Jiao DM, Wang Y, Song J, Wu JH, Wu LJ, et al. Integrated microRNA and gene expression profiling reveals the crucial miRNAs in curcumin anti-lung cancer cell invasion. Thoracic cancer. 2017; 8: 461-70.

125. Lu Y, Wang J, Liu L, Yu L, Zhao N, Zhou X, et al. Curcumin increases the sensitivity of Paclitaxel-resistant NSCLC cells to Paclitaxel through microRNA-30c-mediated MTA1 reduction. Tumour biology : the journal of the International Society for Oncodevelopmental Biology and Medicine. 2017; 39: 1010428317698353

126. Liu WL, Chang JM, Chong IW, Hung YL, Chen YH, Huang WT, et al. Curcumin Inhibits LIN-28A through the Activation of miRNA-98 in the Lung Cancer Cell Line A549. Molecules. 2017; 22: 929.

127. Liu J, Li M, Wang Y, Luo J. Curcumin sensitizes prostate cancer cells to radiation partly via epigenetic activation of miR-143 and miR-143 mediated autophagy inhibition. Journal of drug targeting. 2017; 25: 645-52.

128. Wang J, Ying G, Wang J, Jung Y, Lu J, Zhu J, et al. Characterization of phosphoglycerate kinase-1 expression of stromal cells derived from tumor microenvironment in prostate cancer progression. Cancer research. 2010; 70: 471-80.

129. Cao H, Yu H, Feng Y, Chen L, Liang F. Curcumin inhibits prostate cancer by targeting PGK1 in the FOXD3/miR-143 axis. Cancer chemotherapy and pharmacology. 2017; 79: 985-94.

130. Toden S, Okugawa Y, Jascur T, Wodarz D, Komarova NL, Buhrmann C, et al. Curcumin mediates chemosensitization to 5-fluorouracil through miRNA-induced suppression of epithelial-to-mesenchymal transition in chemoresistant colorectal cancer. Carcinogenesis. 2015; 36: 355-67.

131. Sun Q, Zhang W, Guo Y, Li Z, Chen X, Wang Y, et al. Curcumin inhibits cell growth and induces cell apoptosis through upregulation of miR-33b in gastric cancer. Tumour biology : the journal of the International Society for Oncodevelopmental Biology and Medicine. 2016; 37: 13177-84.

132. Ye M, Zhang J, Zhang J, Miao Q, Yao L, Zhang J. Curcumin promotes apoptosis by activating the p53-miR-192-5p/215-XIAP pathway in non-small cell lung cancer. Cancer letters. 2015; 357: 196-205.

133. Chen P, Wang H, Yang F, Chen H, He W, Wang J. Curcumin Promotes Osteosarcoma Cell Death by Activating miR-125a/ERRalpha Signal Pathway. Journal of cellular biochemistry. 2017; 118: 74-81.

134. Yu D, An F, He X, Cao X. Curcumin inhibits the proliferation and invasion of human osteosarcoma cell line MG-63 by regulating miR-138. International journal of clinical and experimental pathology. 2015; 8: 14946-52.

135. Xiao C, Wang L, Zhu L, Zhang C, Zhou J. Curcumin inhibits oral squamous cell carcinoma SCC-9 cells proliferation by regulating miR-9 expression. Biochemical and biophysical research communications. 2014; 454: 576-80.

136. Ma J, Fang B, Zeng F, Pang H, Zhang J, Shi Y, et al. Curcumin inhibits cell growth and invasion through up-regulation of miR-7 in pancreatic cancer cells. Toxicology letters. 2014; 231: 82-91.

137. Dhillon N, Aggarwal BB, Newman RA, Wolff RA, Kunnumakkara AB, Abbruzzese JL, et al. Phase II trial of curcumin in patients with advanced pancreatic cancer. Clinical cancer research : an official journal of the American Association for Cancer Research. 2008; 14: 4491-9.

138. Bayet-Robert M, Kwiatkowski F, Leheurteur M, Gachon F, Planchat E, Abrial C, et al. Phase I dose escalation trial of docetaxel plus curcumin in patients with advanced and metastatic breast cancer. Cancer biology \& therapy. 2010; 9: $8-14$

139. He ZY, Shi CB, Wen H, Li FL, Wang BL, Wang J. Upregulation of p53 expression in patients with colorectal cancer by administration of curcumin. Cancer investigation. 2011; 29: 208-13.

140. Maciocia N, Wechalekar A, Yong K. Monoclonal gammopathy of undetermined significance (MGUS) and smoldering myeloma (SMM): a practical guide to management. Hematological oncology. 2017; 35: 432-9.

141. Golombick T, Diamond TH, Manoharan A, Ramakrishna R. Monoclonal gammopathy of undetermined significance, smoldering multiple myeloma, and curcumin: a randomized, double-blind placebo-controlled cross-over $4 \mathrm{~g}$ study and an open-label $8 \mathrm{~g}$ extension study. American journal of hematology. 2012; 87: 455-60

142. Mahammedi H, Planchat E, Pouget M, Durando X, Cure H, Guy L, et al. The New Combination Docetaxel, Prednisone and Curcumin in Patients with Castration-Resistant Prostate Cancer: A Pilot Phase II Study. Oncology. 2016; 90: 69-78

143. Pastorelli D, Fabricio ASC, Giovanis P, D'Ippolito S, Fiduccia P, Solda C, et al. Phytosome complex of curcumin as complementary therapy of advanced pancreatic cancer improves safety and efficacy of gemcitabine: Results of a prospective phase II trial. Pharmacological research. 2018; 132: 72-9.
144. Tempero M, Plunkett W, Ruiz Van Haperen V, Hainsworth J, Hochster $H$, Lenzi R, et al. Randomized phase II comparison of dose-intense gemcitabine: thirty-minute infusion and fixed dose rate infusion in patients with pancreatic adenocarcinoma. Journal of clinical oncology : official journal of the American Society of Clinical Oncology. 2003; 21: 3402-8.

145. Cruz-Correa M, Shoskes DA, Sanchez P, Zhao R, Hylind LM, Wexner SD, et al. Combination treatment with curcumin and quercetin of adenomas in familial adenomatous polyposis. Clinical gastroenterology and hepatology : the official clinical practice journal of the American Gastroenterological Association. 2006; 4: 1035-8.

146. Kanai M, Yoshimura K, Asada M, Imaizumi A, Suzuki C, Matsumoto S, et al. A phase I/II study of gemcitabine-based chemotherapy plus curcumin for patients with gemcitabine-resistant pancreatic cancer. Cancer chemotherapy and pharmacology. 2011; 68: 157-64.

147. Kashyap D, Tuli HS, Garg VK, Goel N, Bishayee A. Oncogenic and Tumor-Suppressive Roles of MicroRNAs with Special Reference to Apoptosis: Molecular Mechanisms and Therapeutic Potential. Molecular diagnosis \& therapy. 2018; 22: 179-201.

148. Huarte M. The emerging role of lncRNAs in cancer. Nature medicine. 2015; 21 : 1253-61.

149. Tomeh MA, Hadianamrei R, Zhao X. A Review of Curcumin and Its Derivatives as Anticancer Agents. International journal of molecular sciences. 2019; 20: 1033 